\title{
Community Resources for Learning: How Capuchin Monkeys Construct Technical Traditions
}

\section{Dorothy M. Fragaszy}

\section{Biological Theory}

ISSN 1555-5542

Biol Theory

DOI 10.1007/s13752-012-0032-8

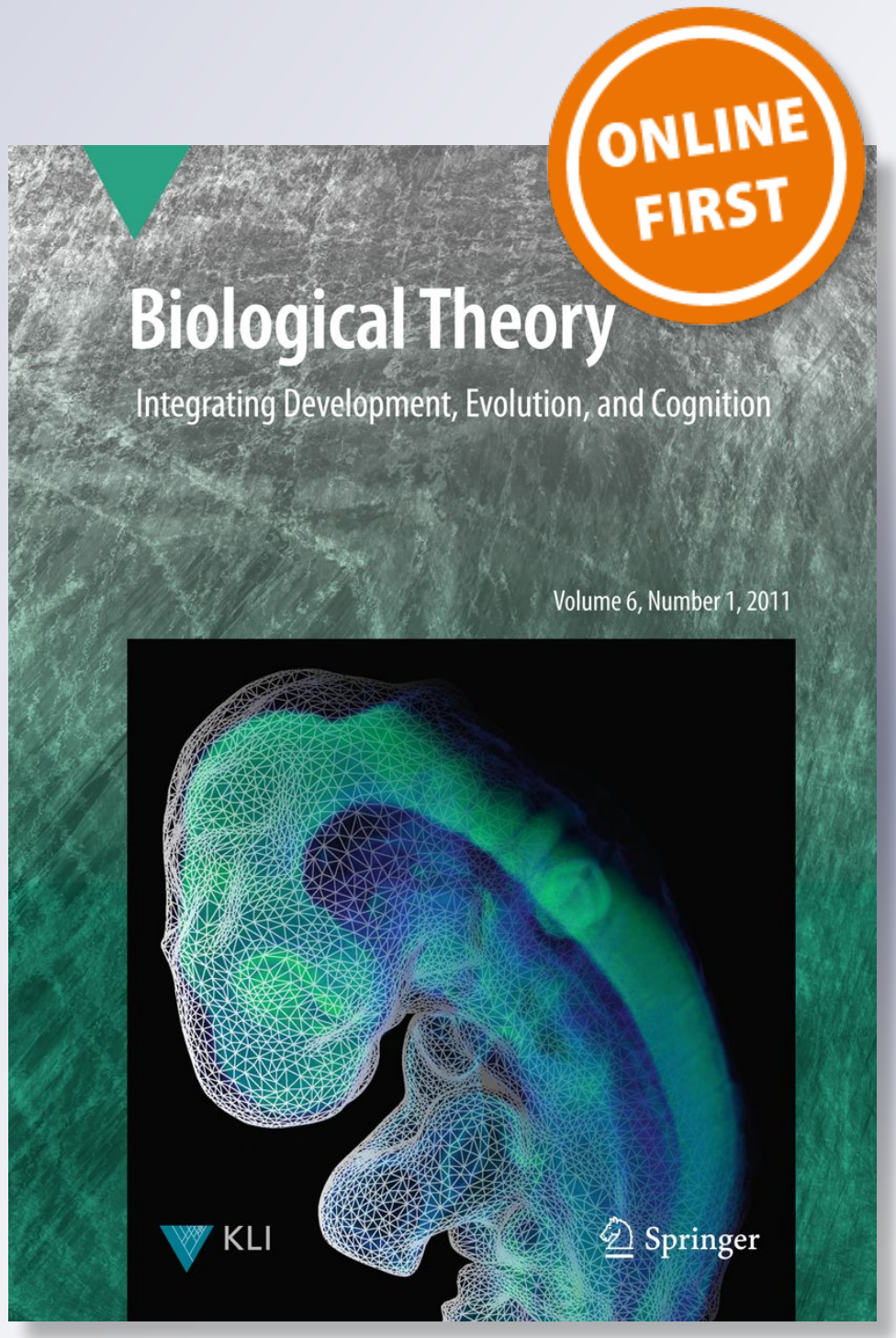

拦 Springer 
Your article is protected by copyright and all rights are held exclusively by Konrad Lorenz Institute for Evolution and Cognitive Research. This e-offprint is for personal use only and shall not be self-archived in electronic repositories. If you wish to selfarchive your work, please use the accepted author's version for posting to your own website or your institution's repository. You may further deposit the accepted author's version on a funder's repository at a funder's request, provided it is not made publicly available until 12 months after publication. 


\title{
Community Resources for Learning: How Capuchin Monkeys Construct Technical Traditions
}

\author{
Dorothy M. Fragaszy
}

Received: 26 February 2012 / Accepted: 30 May 2012

(c) Konrad Lorenz Institute for Evolution and Cognition Research 2012

\begin{abstract}
The developmental importance to humans of the human-constructed physical environment, including myriad modified natural objects or manufactured objects, is well recognized. The importance of the physical dimension of the constructed niche has also been recognized in nonhuman animals with respect to dwellings (e.g., beavers' dams, birds' nests, and bees' hives), but has not previously been applied to technical traditions, despite the fact that enduring alterations of the physical environment left by social partners are part of the constructed niche that supports the learning of technical skills through the phenomenon of delayed social facilitation. These alterations aid learning over a longer time scale than the actions themselves. Thus, technical skills that result in enduring physical artifacts, which themselves aid learning the skills, should be both more persistent in a population and more widespread than technical skills that do not share this feature. This perspective gives us a new lens through which to understand the origins of technical traditions in nonhuman animals, and by extension, in human ancestors. Understanding the process by which traditional technical skills are acquired in nonhuman species gives us insight into the ways that the combination of social and physical niche construction can support the evolution of technical aspects of culture from modest beginnings.
\end{abstract}

Keywords Artifacts - Capuchin monkeys ·

Niche construction - Ontogenetic niche .

Social transmission $\cdot$ Tool use $\cdot$ Tradition

D. M. Fragaszy ( $\bowtie)$

Department of Psychology, University of Georgia, Athens, GA, USA

e-mail: doree@uga.edu
Niche construction theory (NCT) (Odling-Smee et al. 2003) posits that organisms, through their activities and choices, modify their own habitats and resources as well as the niches of other species in their immediate environment. The effects of an individual's activities on its environment can modify selection pressures for itself and its conspecifics as well as for other species living in its environs (see Laland and O'Brien 2012, this issue). Thus, according to NCT, animals are active participants in their own evolution. Particularly when individuals produce enduring changes in the environment, their activities result in "intergenerational persistence" (Laland and O'Brien 2012, this issue) of constructed niches. One significant manner in which this happens is through maintenance of a heritable "ontogenetic niche," to use West et al.'s (1988) phrase, that frames development across generations. West and King (2008, p. 384) describe the ontogenetic niche, and the significance of sociality to the nature of the ontogenetic niche, in this way: "At a behavioral level, the ontogenetic niche is the set of ecological and social circumstances inherited by individuals. Exogenetic heredity can be highly reliable, probable and stable over generations, e.g., inheriting conspecifics is as dependable as inheriting genes."

For many animals, the ontogenetic niche prominently features social components, such as parents, siblings, and group mates. The ontogenetic niche shapes individuals' opportunities for learning, particularly for learning skills and habits characteristic of other members of their social group (Jablonka and Lamb 2005). Thus, this feature of constructed niches underlies traditions, defined as behaviors learned anew by each generation, where such learning is aided by social context (Fragaszy and Perry 2003). In common parlance, social learning supports the maintenance of traditions in animals, and the social setting in which young animals develop shapes the traditions they will acquire. 
Odling-Smee et al. (2003) point out that most documented cases of social learning among nonhumans concern "horizontal" influences, where individuals influence their current companions in the immediate present in ways that promote behavioral matching and group cohesion (e.g., facilitating feeding or enhancing interest in or fear of an object or event; Galef 1988; Coussi-Korbel and Fragaszy 1995). In long-lived highly social species, however, much social learning is prominently directional: young individuals learn in the presence of older, skilled others. This pattern has been characterized as "vertical transmission" when young individuals learn from parents (Laland et al. 1993) and "oblique" when many members of the parental generation serve as resources for the younger generation (Sterelny 2010). Social learning may be supported by specialized attentional processes on the part of the young learner coupled with specialized deictic behaviors (such as pointing, performing actions in an exaggerated and slow manner, or repeating them) on the part of adults which prime the young individuals to attend to their actions. This pattern has been theorized to characterize, and to be specific to, humans (Gergely et al. 2007). However, even in the absence of specialized deictic behaviors, nonhuman species also show more powerful social learning by young individuals than by older individuals, with the net result that young individuals learn the skills of the older generation or older siblings (e.g., black rats learning to strip the seeds from pine cones; Terkel 1996). Older individuals are resources-community resources-for learning for younger individuals.

My particular concern here is with technical traditions, such as using hand tools. It is taken for granted that humans typically learn technical skills through a process that includes social learning. Technical skills are learned by practice; they involve specialized actions, control of objects held in the hand, and so forth, and can take many years to master (such as knapping glass beads, as documented by Bril et al. 2005). Like all traditions, learning these skills is aided by the activities of others. Often we consider the aid provided by others to be behavioral, such as teaching, demonstrating, or simply doing while younger individuals watch. These are certainly powerful aids to children's learning (Rogoff 1991), but the species-typical developmental environment that supports technical traditions in humans also contains omnipresent constructed physical settings and artifacts (in the sense of enduring physical objects) created through or altered by adults' activities. Children grow up surrounded by the artifacts of adult living, such as clothing, furniture, shelters, musical instruments, and tools for food preparation, agriculture, hunting, and personal hygiene. They are constantly exposed to these artifacts, and they participate in their use as they become able to do so. We do not wonder that children learn to use artifacts, including basic hand tools, and master their culture's technical skills of daily living in a few short years, and we do not question that the development of these technical skills reflects both the supportive influence of adult activity (through modeling, teaching, or both) and practice, sometimes when adults are not performing these skills.

Some species of nonhuman primates display putative technical traditions, such as using tools in foraging (reviewed in Shumaker et al. 2011). Although adults in these species do not teach youngsters skills, such as how to use tools, in those cases where the development of tool use has been studied, it appears that youngsters acquire these skills in a deeply supportive social context. For example, Humle et al. (2009) describe the context in which young chimpanzees in Bossou, Guinea, learn to dip for ants, a hazardous behavior that can result in painful stings, especially when conducted at the ants' nest. Mothers with young infants differentially dipped for ants along the ants' trails (a less risky activity), where infants had a better opportunity to watch closely and to participate themselves than they do at the ants' nest. Infants whose mothers devoted more time to ant dipping began to dip themselves at a younger age than those whose mothers dipped for less time. Crucially for the argument that the presence of artifacts aids youngsters' learning of the skill, infants dipped exclusively with tools used but abandoned by others during the same dipping session. Adults, in contrast, used new tools in more than three-quarters of their sessions ( $\mathrm{T}$. Humle, personal communication, 18 February 2012). Thus, infants' initial efforts to practice dipping were enabled by the availability of pre-used (and hence, pre-selected as suitable) tools.

In the language of NCT, the inherited ontogenetic niche of humans includes opportunities provided by others for learning traditional technical skills, including the use of tools (see Kendal 2012, this issue). Does niche construction afford the same support for technical traditions in nonhuman species? It appears that it does for the chimpanzees at Bossou, as Humle et al. (2009) have shown. Below I review several studies that suggest the same applies to tufted capuchin monkeys (genus Sapajus) ${ }^{1}$ from South America, which are far from the hominid lineage (see also Visalberghi and Fragaszy 2012).

\footnotetext{
${ }^{1}$ Recent molecular analysis has revealed that capuchin monkeys, formerly identified as the single genus Cebus, are two genera, with the robust forms, including C. libidinosus, C. xanthosternos, and several other species, now recognized as the genus Sapajus and the gracile forms retained as the genus Cebus (Lynch-Alfaro et al. 2011, 2012). To date, tool use has been observed in some species of wild Sapajus but in no species of wild Cebus. We retain the genus designation of Cebus for published works cited here that used that designation.
} 
Before going further, we need to define "tradition" and "technical skill." A tradition is an enduring behavior pattern shared among members of a group that depends to a measurable degree on social contributions to learning (Fragaszy and Perry 2003). A skill, following Bernstein (1967, 1996), is a task-specific coordinative structure of movements that allows an actor to achieve his/her goal smoothly, effectively, and with flexible adaptation to variations (as in catching a ball thrown to different locations across successive throws). A technical skill allows one to accomplish specific specialized tasks, such as operating specific machinery. As I use the term here, a technical skill refers to a set of actions with a specialized goal that incorporates action on or with physical elements. Thus a technical tradition is a set of skilled behaviors used to accomplish a specific goal, involving actions on or with objects or substrates, the acquisition of which depends to a measurable degree on social contributions to learning.

The studies with capuchin monkeys illustrate how social partners influence young monkeys' development of technical skills and how enduring alterations of the physical environment left by social partners are part of the environment in which young monkeys learn these skills. By identifying enduring physical traces that accompany traditional technical activities in nonhumans, and considering how such traces scaffold the learning experience of the novice, the characteristics of the ontogenetic niche supporting technical traditions will become clearer. Specifying the elements of the ontogenetic niche that support technical traditions can help us model the temporally and geographically uneven appearance and disappearance of technical traditions in extant nonhuman primates and, by extension, the uneven presence of specific technical traditions in ancestral humans. This is because technical behaviors providing enduring physical traces (artifacts) that positively impact skill acquisition of novices are likely to be more widespread and more enduring than more "cryptic" skills that produce no or transient artifacts. Compared to skilled activities that do not produce artifacts, skilled activities that provide enduring artifacts should be easier to learn, other things being equal, because the artifacts produced by the activity of one generation scaffold learning of the skill by the next generation.

\section{A Technical Tradition in Captive Capuchin Monkeys}

Crast et al. (2010) showed that a technical tradition can be induced in captive tufted capuchin monkeys (Cebus apella spp.). The tradition in question is how to operate a mechanical device that delivers juice. Briefly, in a baseline phase (20 half-hour sessions), young monkeys in two social groups had the opportunity to explore a device that could be operated in two ways to obtain juice. It could be extracted from one reservoir by pumping a lever and from the other by turning a recessed wheel. In the baseline phase, the apparatus was present in an area that adults could not enter (termed a crèche) but youngsters (7-18 months) could enter freely (Fig. 1). At the conclusion of 20 sessions, just 2 of 16 youngsters had obtained juice once or twice. An experimental phase followed (for 12 half-hour sessions), in which each group encountered
Fig. 1 Layout of the experimental conditions used by Crast et al. (2010) to induce a technical tradition (operating a device that delivered juice) in captive tufted capuchin monkeys. Reprinted with permission

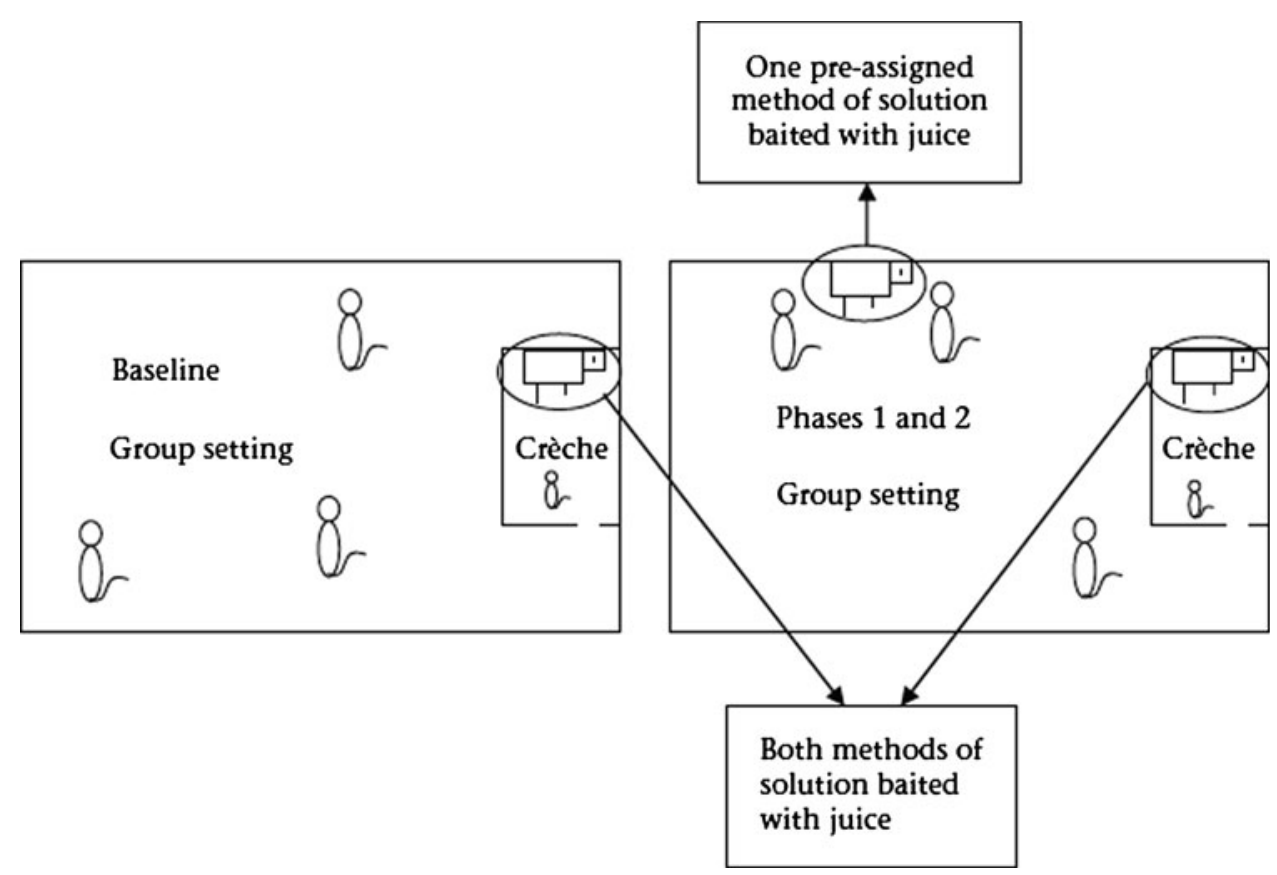


the apparatus simultaneously in the crèche and in the main enclosure, where all group members could work on it. In the main enclosure, only one reservoir was filled (the wheel reservoir was filled in one group, the lever reservoir was filled in the other group). When adults could access the apparatus, several adults and seven youngsters operated it to obtain juice.

This result is congruent with positive social support for the youngsters learning a skill, but it is weak evidence. The greater success of infants in phase 1 compared to the baseline could reflect increasing experience as well as the benefit of skilled partners. More convincing evidence that the presence of a skilled partner aids in learning the technical skill resulted from comparing the first cohort of infants and a later one (in experimental phase 2), studied 2 years later. The young monkeys in phase 2 did not have the benefit of the baseline phase, but the adults in each group were already proficient in one method of working the device when the young monkeys first encountered it. In phase 2 , the young monkeys could encounter the apparatus on their own in the crèche, with both reservoirs filled (and thus both methods could be used to obtain juice), or in the presence of proficient adults, where just one reservoir was filled (so that only one method worked). As in phase 1, the lever reservoir was filled in half the groups; the wheel reservoir was filled in the other groups. Under these circumstances, all 11 young monkeys picked up the skill, and they did so in one or two trials, significantly more quickly than youngsters in the first cohort. While in the crèche, five of the monkeys used only the method used by adults in their group; four others used predominantly the group method. Figure 2 illustrates the typical close observation of proficient adults that youngsters maintained.

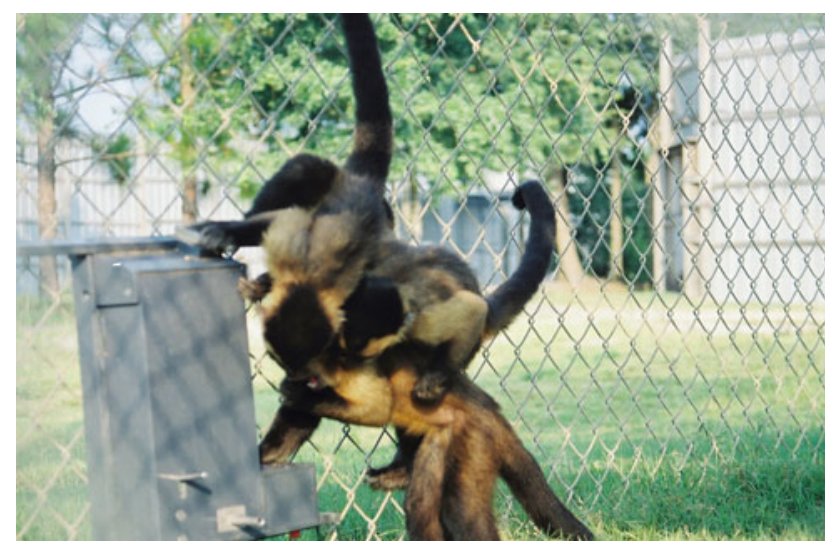

Fig. 2 The social context in which young tufted capuchin monkeys quickly learn how to operate a device that vends juice (Crast et al 2010). In this photo, they are watching an adult use a scalloped wheel recessed in a reservoir that, when turned with the fingers, brings a small quantity of juice within reach of the fingertips
The findings from phase 2 confirm that something in the social setting supported the youngsters' learning the technical skill. They give confidence that monkeys in natural settings may also have technical traditions, but they do not tell us what aspects of a proficient partner or partners encourage the novice to learn a technical skill. We strongly suspect (and are in the process of analyzing our video data to examine the hypothesis) that enduring physical traces (dripped juice) provided by others' activity supported the young monkeys' continuing investigation of the apparatus, and thus supported discovery of how to obtain juice. That is, an individual obtaining juice inevitably left dribbles of juice behind, on the apparatus and on whatever surface lay below it (often including other monkeys). These briefly enduring physical traces provided others approaching the apparatus with strong motivation to investigate it and its environs, which they did eagerly with hands and mouths. We suspect that these remains are one reason why the young monkeys quickly learned to use this apparatus after others in their group did so. If so, then social influence was not mediated solely by watching others as they acted on the apparatus but rather by the full complement of perceptual and action systems geared to discovering how to solve mechanical problems, i.e., how to act on the physical environment to obtain food.

\section{Foraging for Larvae Hidden Inside Bamboo Stalks}

Gunst and colleagues $(2008,2010)$ describe how young wild brown capuchins (C. apella) learn to find and retrieve beetle larvae located inside stalks of bamboo (Guadua latifolia) and thus hidden from view. Obtaining larvae from their tough, concealing substrate requires selecting an appropriate bamboo stalk, locating the larvae hidden inside (both components of searching), and ripping the stalk open and extracting the larvae (handling components) (Fig. 3). Locating an appropriate stalk and an appropriate site on the stalk is not easy because the areas of bamboo that contain larvae do not differ in external appearance from areas lacking larvae. Choosing the right spot to open is important to the monkey because ripping the stalk open requires strength and is time-consuming. The larvae are scattered thinly in the bamboo patch, and it behooves the forager to direct ripping activity to where larvae might be present. Monkeys reach adult efficiency at this foraging taskobtaining five to six larvae per hour allocated to searching for larvae-at about 5 years of age, although they devote considerable time to inspecting and opening bamboo stalks from about 1 year of age.

Gunst and colleagues' $(2008,2010)$ study shows how social partners' alteration of the physical environment channel the young monkeys' development of skill in 
Fig. 3 Young capuchin monkey watches an adult open a bamboo cane $(\mathbf{a}, \mathbf{b})$ and delicately extract a beetle larva (c). The youngster then explores the open cane, although only one larva inhabits each node, and the monkey that opened the cane extracted the larva $(\mathbf{d})$. Opened canes remain available for inspection and exploration for weeks. Photos courtesy of Noelle Gunst
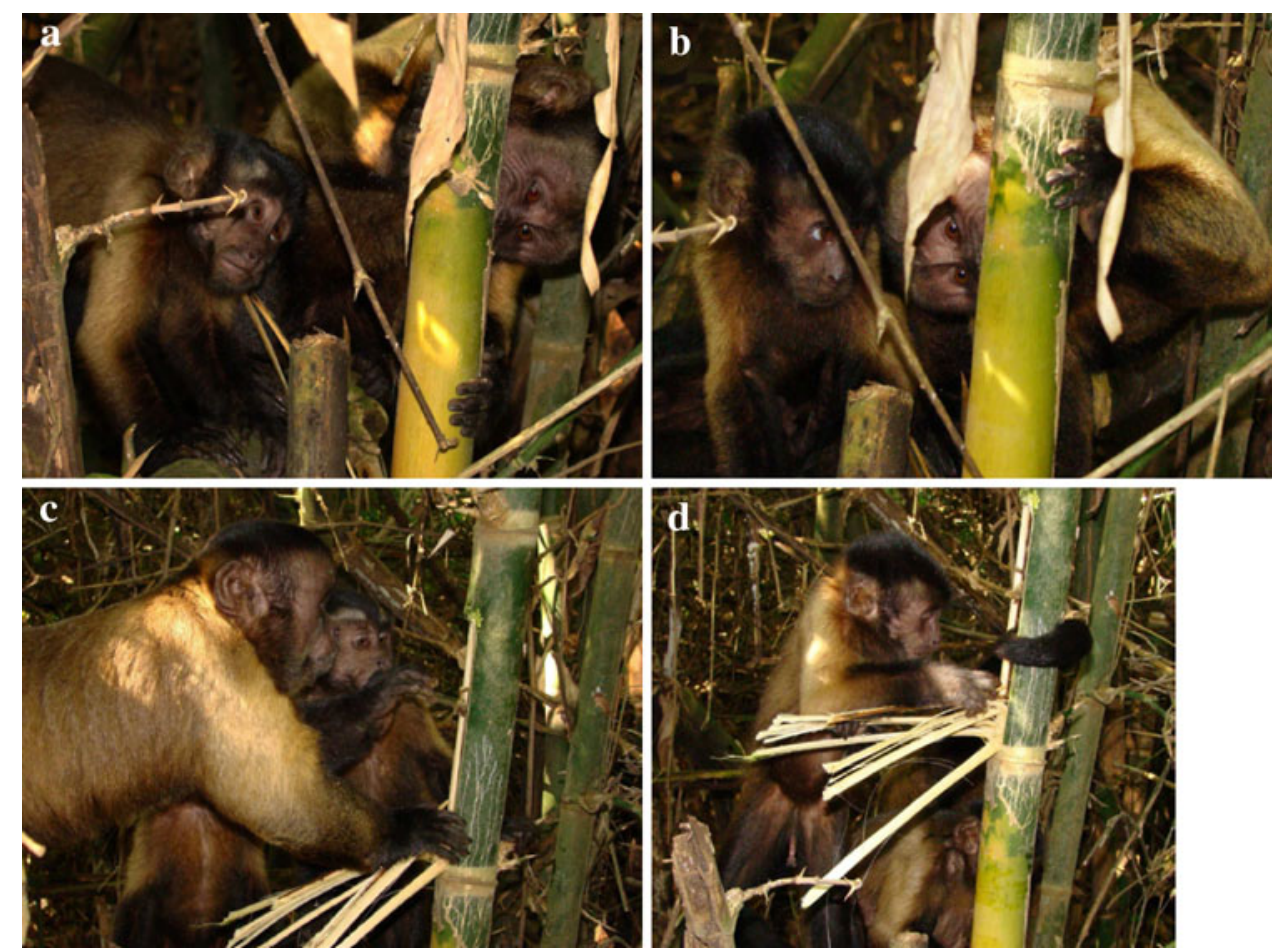

obtaining larvae. Young monkeys are attracted to canes already opened by adults, and at these sites they practice behaviors that contribute to finding and obtaining larvae (Fig. 4). Specifically, immature monkeys performed significantly more larvae-related foraging behaviors (rapidly tapping the cane with the fingertips - called tap scanninginspecting the cane with fingers or nose, biting into and ripping bamboo stalks apart) within 2 min after approaching a ripped bamboo stalk left by a skilled forager than they did in the $2 \mathrm{~min}$ before. In contrast, experienced foragers inspected ripped bamboo stalks briefly and did not follow inspection with biting or ripping. Thus, the physical traces left by skilled foragers apparently stimulate in youngsters just those activities that are most likely to contribute to the acquisition of the foraging skill at hand. In short, skillful individuals "leave the landscape littered with prepared 'practice' sites that appeal to younger monkeys" (Gunst et al. 2008, p. 21). Physical traces are an enduring form of niche construction, and the young monkeys' response to physical traces after others have left the scene is delayed, indirect social facilitation, where social facilitation is defined (Clayton 1978) as the increased probability of one individual performing a behavior (already in its repertoire) when in the presence of another individual performing that behavior.

The construct of social facilitation is expanded in an important sense here to incorporate behavioral facilitation associated with artifacts, at a time distant from when the artifact was produced. Definitions of social facilitation and

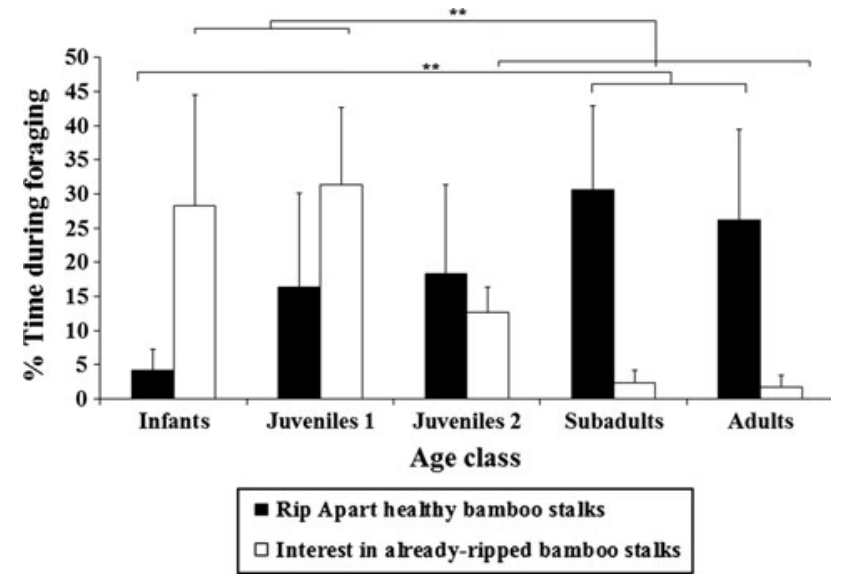

Fig. 4 Mean and standard deviation of foraging time devoted to ripping apart healthy bamboo stalks and showing interest in alreadyripped bamboo stalks for each age class. $* * p<0.01$. Reprinted from Gunst et al. (2010)

related terms (e.g., coaction, social enhancement, stimulus enhancement; Galef 1988; Zentall 2006) are couched in terms of increased probability of a behavior concurrent with or immediately following perception of its performance by another. Galef (1988) includes residual traces emitted by others in the category of social enhancement, giving the example of chemicals (such as ants' trails). Although some scent deposits may last hours or perhaps days, in general, emitted chemicals produce ephemeral traces compared to the physical alterations of objects and 
surfaces produced by technical activity. Facilitation induced by enduring physical artifacts can be long distant in time (and space) from the actions and individuals producing the artifact. I return to this theme below in relation to Jeffares' (2010) suggestion that tools serve as cognitive prompts for the individual holding them.

Ripping open bamboo may seem challenging to us, but for the monkeys, the most challenging part of obtaining larvae is locating the prey item while it is hidden in the bamboo. Social context could help the monkeys learn how to detect the presence of a larva inside a cane, but the aid must be somewhat indirect. For example, through their attraction to the sites where others have already opened canes and extracted larvae, youngsters could learn to notice the presence of the tiny hole made by an insect while laying eggs that develop into larvae or the odor associated with the larvae. Similarly, from watching adults searching, they could learn that tapping serves as a relatively reliable cue about the presence of larvae inside the stalk. But they will not find a larva by investigating the empty site from which an adult has removed the larva. We do not know exactly what the young monkeys learn from their observation of others working in the bamboo or from their persistent inspection of already-opened canes. It may be as generic as the positive value of bamboo canes and the pleasure of opening them. To determine how social partners contribute to skill learning, we should relate individual differences in skill development with individual histories of watching others opening canes and with investigating previously opened canes, as Humle et al. (2009) have done for young chimpanzees learning to dip for ants. This general argument about the data needed to evaluate the contribution of social features to learning a behavior applies to all behaviors. Comparing behavior across groups cannot tell us about the developmental origins of a behavior, and thus such comparisons provide an inadequate basis to determine if a behavior is a tradition (Fragaszy and Perry 2003).

\section{Cracking Palm Nuts Using Hammers and Anvils}

Bearded capuchin monkeys (S. libidinosus) living in the savannah (Cerrado) of Brazil crack tough palm nuts using large stones as hammers and stone or log surfaces as anvils (Fragaszy et al. 2004). Our team has studied this phenomenon at a field site in the state of Piuaí, Brazil (Fazenda Boa Vista, hereafter FBV; see http://EthoCebus.net for information about this project). At FBV, the monkeys crack several species of palm nuts, all of which are too resistant to bite open, even though the monkeys generate extremely strong bite forces (Wright et al. 2009). Most adults crack these nuts using stone hammers routinely across the year (Spagnoletti et al. 2011). However, juveniles less than 4 or 5 years old rarely manage to crack a whole nut, although they manipulate nuts and stones frequently and in the vicinity of adults cracking nuts more frequently than other objects.

The technical components of nut cracking include, among other things, placement of the nut on the anvil surface, striking actions that hit the nut but do not displace it and are of sufficient force to crack the shell, controlling the stone throughout the striking cycle, catching the nut as it rolls following the strike so it does not fall off the anvil, and separating the pieces of endosperm from the shell when the nut is partially cracked (Fragaszy et al. 2010b). The monkeys use a bipedal stance during most of this activity, which is a challenging problem for dynamic balance (Liu et al. 2009). Monkeys are selective about which anvil to use (Liu et al. 2011) and which stone to transport to an anvil, if it lacks a stone (Visalberghi et al. 2009a; Fragaszy et al. 2010a; Massaro et al. 2012). Overall, it is no surprise that it takes young monkeys years to master nut cracking. Young monkeys, from a very young age and for several years, devote considerable time and effort to watching their elders crack nuts (Fig. 5) and practicing percussive actions with bits of nut and small stones (Fig. 6).

Nut cracking is a noisy, vigorous activity, and the sound and motion attract youngsters. They may watch from some distance, or they may stay near the anvil while another is cracking, sometimes handling smaller stones and nutshells in the vicinity. They may take pieces of nuts cracked by others while the others are still at the anvil. They spend a great deal of time in this permissive social setting. Eventually, when proficient tool users leave their hammers and/ or partially opened nuts on the anvils, youngsters use them to "practice," if they are strong enough to lift the hammer stones (which may weigh more than the young monkeys

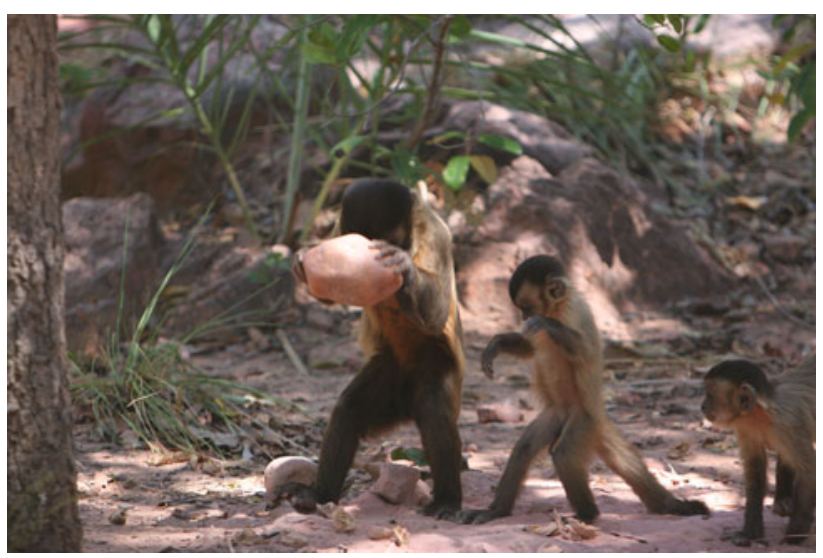

Fig. 5 Adult bearded capuchin cracking a nut using a large hammer stone, while two juveniles watch with interest. This is a very common event at Fazenda Boa Vista, Brazil. Photo by Barth Wright 


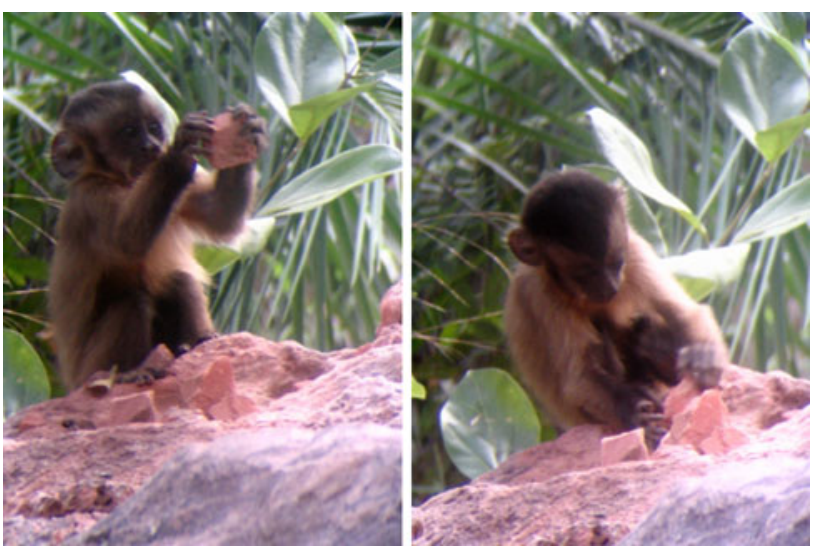

Fig. 6 Young bearded capuchin monkey (about 5 months old) banging a small stone. Young monkeys practice percussion in this manner for years before they can crack open a nut. Photos by Marino Gomes de Oliveira

trying to lift them). If not, they may strike one nut on another one.

Adult monkeys leave enduring physical traces of nut cracking. First, the nuts leave a fragrant oily residue on the stones and anvil surfaces where they have been smashed. Young monkeys sniff and lick these areas. Second, the cracking process produces cracked shells, which often contain small bits of kernel. Young monkeys collect these, sniff, pick, and nibble at the contents and bang them directly on any convenient surface (stone, ground, or tree). Sometimes this treatment cracks another bit of shell or otherwise knocks loose another fragment of kernel. It is easy to see that adults litter the area with materials that keep young monkeys interested in nuts and their contents and in the sites where the nuts are cracked. Nutshells, cracked and otherwise, persist in the environment at FBV for years, even being preserved in the strata as archeological materials and exposed to natural weathering (Haslam, Visalberghi, and Fragaszy, unpublished data [June 2011, Primate Archeology in Brazil]).

In addition to attracting youngsters to sites where nuts are cracked, adults leave youngsters with key artifacts that support learning to crack nuts. Perhaps the most important physical features that others prepare for young monkeys have to do with the tools used to crack. The hammer stones are rare in the landscape; they are of different composition than the predominant sandstone (Visalberghi et al. 2007; Visalberghi et al. 2009b). However, there are abundant anvil sites (hundreds in the home range of one of our study groups), and an operational anvil site includes an adequate hammer stone. These stones have been carried to the anvil site by the monkeys and left there after use (or transported to another anvil site; hammer stones remain in circulation). Thus a young monkey arriving at an anvil site finds the tool used by the previous cracker (Visalberghi et al. 2007).
A second critical physical aid is the ubiquitous debris of cracking - the bits of cracked shells. Young monkeys begin cracking by re-cracking small pieces of shell, which they can fracture. Only later do they manage to crack whole nuts.

In sum, we suggest that the cracking activities of others can positively bias learners' activity indirectly and over a long temporal scale, even when group members are not presently cracking nuts, through the production of enduring physical traces and technical artifacts. These materials support persistent practice during years in which young monkeys cannot crack nuts themselves. Ongoing cracking can also influence youngsters' behavior, and thus learning, but this influence occurs over a shorter time scale, perhaps minutes as opposed to years. Another important benefit of enduring physical traces compared to observation of ongoing cracking concerns social dynamics. Monkeys compete for food, and most adults do not tolerate juveniles over 2 years of age close to them as they crack. Juveniles less than 2 years old typically can approach and remain near an adult cracking nuts at an anvil without fear of displacement. Older juveniles do, however, watch from a distance, and they linger at cracking sites after others have left, at which point they have unfettered access to hammers and anvils. Frequently they wait patiently for more dominant and older individuals to finish, and when these individuals leave (or the juveniles arrive at an anvil site without adults nearby), the juveniles take their turn at cracking (Spagnoletti et al. 2012). Temporally extended influence arising from enduring physical traces and technical artifacts creates a supportive physical environment for these older juveniles.

Might young monkeys learn to crack nuts, or improve their technique, from directly copying some aspect of the behavior of others? Field observations cannot answer this question decisively, but we think the answer is no. Pounding because another monkey is pounding is one entry point for skill development, but simply pounding a stone on a nut is not sufficient to crack it. Even after a young monkey reliably produces all the relevant actions in the correct sequence, it takes another year or more before it succeeds in cracking a whole nut. The trajectory of the stone, the force with which it strikes the nut, and the position of the nut in the anvil all affect success and are not extractable from seeing the action performed. Instead, the monkeys require persistent individual practice (and sufficient body mass) to optimize trajectory, force, positioning, and so forth. Having proficient group members watch could contribute to skill development over this long period, not because young monkeys learn anything specific from watching others but because watching others, like encountering physical traces of their activity, increases the motivation to act and channels the choice of elements with which to act toward the ones that support effective practice. 
This natural history of nut cracking suggests but does not prove that physical traces and artifacts support the technical tradition of nut cracking. Nor are we able yet to say anything about the relative contribution of observing or hearing others cracking in the short term versus encountering artifacts outside of periods when others are cracking, or whether the combination of the two is particularly efficacious, as seems likely. We are now working to collect that evidence.

\section{Artifacts and the Occurrence of Technical Traditions}

The prevailing view of social learning in nonhuman animals with respect to mechanical or spatial problem solving, as with many other kinds of behavior, emphasizes the value of watching others do something (Zentall 2006; Subiaul 2007). This conception of social learning, however, is too narrow to describe how the activity of others helps young capuchins learn to crack nuts, find larvae, or learn to operate a juice dispenser. The examples reviewed above show that capuchin monkeys prepare the environment in ways that support others learning a particular skill, even when the others are not watching the relevant activity. Enduring physical artifacts, in particular, draw youngsters' interest and focus their activity. This point applies to other species, including humans. Jaffares (2010) argues that tools, as soon as they became durable and re-used (which he puts at the appearance of Homo habilis), began to serve as cognitive primers for the use of these objects. That is, tools become prompts for particular kinds of activities; they remind the individual what to do, where, and why. They also bias attention to some features of the environment rather than others. In a profound way, they change the way one views the world. Jeffares' view is in accord with ecological psychologists' view that cognition is indivisible from action and thus is embedded in the physical world (Gibson 1979; Chemero 2009). In the same way that monkeys can recall shapes when prompted by some other cue in a laboratory task (Basile and Hampton 2011), enduring artifacts (e.g., the anvil, the nuts, or the hammer) may recall the actions of cracking, either observed or performed.

Technical skills may confer some benefit (usually in efficiency of time expenditure, energy savings or gain, or minimization of risk) to those who possess such skills, but the provision of benefit cannot explain the uneven distribution in time and space of technical traditions. We have no evidence that populations of monkeys and apes that possess technical traditions are "smarter" or reproductively fitter than populations of congeners without such traditions. It is more probable that they are simply behaving in ways congruent with their local details of learning-their ontogenetic niche and the local ecology. The learning landscape probably makes the difference between the persistence of a technical tradition versus an ephemeral technical behavior, no matter how beneficial the behavior. However, it appears that the propensity to develop technical traditions varies systematically across taxa together with propensities for social learning and extractive foraging, with large brain size and strong performance on a range of laboratory learning tasks (Reader et al. 2011). Thus physically and socially constructed heritable niches can be seen as products of, and participants in, biological evolution of a general intelligence, as NCT proposes (Odling-Smee et al. 2003).

Can we identify what features of the task-learner system support learning a technical skill? To do this, we might consider the task from the learner's perspective-what information the learner uses to guide behavior and how it obtains that information from looking, listening, touching and manipulating, sniffing, and tasting. Features of the environment that support the learners' efforts to learn about the affordances of actions with the relevant physical elements will aid learning a skill. Enduring physical traces that can be investigated or artifacts that can be handled in task-relevant ways fit the bill. Thus we should be able to induce traditions by manipulating the learning landscape to include artifacts of this sort from prior skilled action, as we have shown to be the case with experimental studies of captive primates.

Other kinds of activities besides tool use also lead to enduring artifacts (e.g., nest construction) that impact the ontogenetic niche of a species. The arguments given above about the value of participation in activity and exposure to relevant materials do not apply exclusively to tools. However, an important characteristic of artifacts associated with tools is that tools invite actions that promote skill development. It is unknown whether other artifacts have a similar activity-inducing effect. This is a topic that deserves ethologists' attention. The timing of the activity is another important consideration. For example, if a bird's nest building occurs before eggs hatch, and the nestlings leave the nest before another nest has to be built, the young bird does not have any opportunity to observe or practice construction of the nest. This artifact does not scaffold activity learning during the period of residence in the nest. Slowly developing species have an advantage in this respect for social contributions to skill development.

\section{Conclusion}

Niche construction is a highway from individual behavior to evolutionary change. For social species, including our own, constructed niches are prominently social in origin. 
Recognizing this, and placing traditions (and culture) into this framework, allows ethology and the human sciences to participate in the extended synthesis of evolutionary theory now well under way (Pigliucci and Müller 2010; Laland and O'Brien 2012, this issue; Sterelny 2012). Constructed niches are an epigenetic mechanism of inheritance and thus can result in relatively quick behavioral evolution mediated by social setting and altered developmental systems. Recognizing all the ways in which social animals construct their environments, and the contributions these constructions have on the development of the next generation, provides a richer view of evolution, of culture, and of the links between culture and evolution. Here I have explored the possible contributions of enduring artifacts of technical activity to the occurrence of technical traditions in nonhuman species. Tools can be enduring artifacts, and they can provide enduring artifacts related to their use. Tool technologies with these properties should be particularly widespread because these properties support learning the technology. This hypothesis, if confirmed, gives us a basis to predict the likelihood of certain kinds of tool use becoming established as traditions in wild populations. Artifactual scaffolds for learning a particular skill may predict technical traditions more accurately than ease of learning the skill in captive settings.

Acknowledgments I thank Kevin Laland and Mike O'Brien for the invitation to participate in the KLI workshop. I thank my fellow participants at that conference for thought-provoking discussions that widened my understanding of niche construction. Thanks to Tatyana Humle for sharing unpublished data and to Noelle Gunst, Yonat Eshchar, and Jessi Crast for their research contributions and assistance with figures. Thanks also to Elisabetta Visalberghi, Sue Boinski, and Patricia Izar for many years of fruitful conversations about capuchins and the research collaborations reported here. My research was supported by grants from the National Science Foundation (BCS0352035), the National Geographic Society Committee on Research and Exploration, the Leakey Foundation, and the University of Georgia.

\section{References}

Basile B, Hampton R (2011) Monkeys recall and reproduce simple shapes from memory. Curr Biol 21:774-778

Bernstein N (1967) The coordination and regulation of movements. Pergamon, Oxford

Bernstein N (1996) On dexterity and its development. In: Latash M, Turvey $M$ (eds) Dexterity and its development. Erlbaum, Hillsdale, pp 3-236

Bril B, Roux V, Dietrich G (2005) Stone-knapping: Khambat (India), a unique opportunity? In: Bril B, Roux E (eds) Stone knapping: the necessary conditions for a uniquely hominin behavior. McDonald Institute for Archeological Research, Cambridge, pp 53-71

Chemero A (2009) Radical embodied cognitive science. MIT Press, Cambridge, MA

Clayton DA (1978) Socially facilitated behavior. Q Rev Biol 53:373-392
Coussi-Korbel S, Fragaszy D (1995) On the relation between social dynamics and social learning. Anim Beh 50:1441-1453

Crast J, Hardy J, Fragaszy D (2010) Inducing traditions in captive capuchin monkeys (Cebus apella). Anim Behav 80:955-964

Fragaszy D, Perry S (2003) Towards a biology of traditions. In: Fragaszy D, Perry S (eds) Traditions in nonhuman animals: models and evidence. Cambridge University Press, Cambridge, pp 1-32

Fragaszy DM, Izar P, Visalberghi E, Ottoni EB, Gomes De Oliveira M (2004) Wild capuchin monkeys (Cebus libidinosus) use anvils and stone pounding tools. Am J Primatol 64:359-366

Fragaszy D, Greenberg R, Visalberghi E, Ottoni EB, Izar P, Liu Q (2010a) How wild bearded capuchin monkeys select stones and nuts to minimize the number of strikes per nut cracked. Anim Behav 80:205-214

Fragaszy D, Pickering T, Liu Q, Izar P, Ottoni E, Visalberghi E (2010b) Bearded capuchin monkeys' and a human's efficiency at cracking palm nuts with stone tools: field experiments. Anim Behav 79:321-332

Galef BG (1988) Imitation in animals: history, definition, and interpretation of the data from the psychological laboratory. In: Zentall T, Galef BG (eds) Social learning: biological and psychological perspectives. Erlbaum, Hillsdale, pp 3-28

Gergely G, Egyed K, Kiraly I (2007) On pedagogy. Dev Sci 10:139-146

Gibson JJ (1979) The ecological approach to visual perception. Houghton Mifflin, Boston

Gunst N, Boinski S, Fragaszy D (2008) Acquisition of foraging competence in wild brown capuchins (Cebus apella), with special reference to conspecifics' foraging artefacts as an indirect social influence. Behaviour 145:195-229

Gunst N, Boinski B, Fragaszy D (2010) Development of skilled detection and extraction of embedded preys by wild brown capuchin monkeys (Cebus apella apella). J Comp Psychol 124:194-204

Humle T, Snowdon C, Matsuzawa T (2009) Social influences on antdipping acquisition in the wild chimpanzees (Pan troglodytes verus) of Bossou, Guinea, West Africa. Anim Cogn 12(Supplement 1):S37-S48

Jablonka E, Lamb M (2005) Evolution in four dimensions. MIT Press, Cambridge, MA

Jeffares B (2010) The co-evolution of tools and minds: cognition and material culture in the hominin lineage. Phenom Cogn Sci 9:503-520

Kendal JR (2012) Cultural niche construction and human learning environments: investigating sociocultural perspectives. Biol Theory 6. doi:10.1007/s13752-012-0038-2

Laland KN, O'Brien MJ (2012) Cultural niche construction: an introduction. Biol Theor 6. doi:10.1007/s13752-012-0026-6

Laland KN, Richerson PJ, Boyd R (1993) Animal social learning: toward a new theoretical approach. Persp Ethol 10:249-277

Liu Q, Simpson K, Izar P, Ottoni E, Visalberghi E, Fragaszy D (2009) Kinematics and energetics of nut-cracking in wild capuchin monkeys (Cebus libidinosus) in Piauí, Brazil. Am J Phys Anthropol 138:210-220

Liu Q, Fragaszy D, Wright B, Wright K, Izar P, Visalberghi E (2011) Wild bearded capuchin monkeys (Cebus libidinosus) place nuts in anvils selectively. Anim Behav 81:297-305

Lynch Alfaro J, Boubli JP, Olson LE, Di Fiore A, Wilson B et al (2011) Explosive Pleistocene range expansion leads to widespread Amazonian sympatry between robust and gracile capuchin monkeys. J Biogeogr 39:272-288

Lynch-Alfaro J, Silva J, Rylands A, Boubli J (2012) How different are robust and gracile capuchin monkeys? An argument for the use of Sapajus and Cebus. Am J Primatol 74:273-286 
Massaro L, Liu Q, Visalberghi E, Fragaszy D (2012) Wild bearded capuchin monkeys select hammer tools on the basis of both stone mass and distance from the anvil. Anim Cogn

Odling-Smee FJ, Laland KN, Feldman MW (2003) Niche construction: the neglected process in evolution. Princeton University Press, Princeton

Pigliucci M, Müller G (eds) (2010) Evolution, the extended synthesis. MIT Press, Cambridge, MA

Reader SM, Hager Y, Laland K. (2011) The evolution of primate general and cultural intelligence. Phil Trans R Soc B 366:1017-1027

Rogoff B (1991) Apprenticeship in thinking. Oxford University Press, New York

Shumaker R, Walkup K, Beck B (2011) Animal tool behavior: the use and manufacture of tools by animals. Johns Hopkins University Press, Baltimore

Spagnoletti N, Visalberghi E, Verderane M, Ottoni E, Izar P, Fragaszy D. (2012). Stone tool use in wild bearded capuchin monkeys, Cebus libidinosus. Is it a strategy to overcome food scarcity? Anim Beh 83:1285-1294

Spagnoletti N, Visalberghi E, Ottoni E, Izar P, Fragaszy D (2011) Stone tool use by adult wild bearded capuchin monkeys (Cebus libidinosus): frequency, efficiency and tool selectivity. J Hum Evol 62:97-107

Sterelny K (2012) The evolved apprentice: how evolution made humans unique. MIT Press, Cambridge, MA

Sterelny K. (2010) Minds: Extended or scaffolded? Phenom Cogn Sci 9:465-481

Subiaul F (2007) The imitation faculty in monkeys: evaluating its features, distribution and evolution. J Anthropol Sci 85:35-62

Terkel J (1996) Cultural transmission of feeding behavior in the black rat, Rattus rattus. In: Galef B, Heyes C (eds) The roots of culture. Academic Press, New York, pp 17-47
Visalberghi E, Fragaszy D (2012). Learning how to forage: Socially biased learning and "niche construction" in wild capuchin monkeys. In: de Waal F, Ferrari P (eds) The primate mind. Harvard University Press, Cambridge MA, pp 81-98

Visalberghi E, Fragaszy D, Ottoni E, Izar P, Oliveira M, Andrade F (2007) Characteristics of hammer stones and anvils used by wild bearded capuchin monkeys (Cebus libidinosus) to crack open palm nuts. Am J Phys Anthropol 32:426-444

Visalberghi E, Addessi E, Truppa V, Spagnoletti N, Ottoni E, Izar P, Fragaszy D (2009a) Selection of effective stone tools by wild bearded capuchin monkeys. Curr Biol 19:213-217

Visalberghi E, Spagnoletti N, Ramos da Silva E, Andrade FRD, Ottoni E, Izar P, Fragaszy D (2009b) Distribution of potential suitable hammers and transport of hammer tools and nuts by wild capuchin monkeys. Primates 50:95-104

West MJ, King A (2008) Deconstructing innate illusions: reflections on nature-nurture-niche from an unlikely source. Philos Psychol 21:383-395

West MJ, King A, Arberg A (1988) The inheritance of niches: the role of ecological legacies in ontogeny. In: Blass EM (ed) Developmental psychobiology and behavioral ecology, vol 9. Plenum, New York, pp 41-62

Wright BW, Wright KA, Chalk J, Verderane M, Fragaszy D, Visalberghi E, Izar P, Ottoni E, Constatino P, Vinyard C (2009) Fallback foraging as a way of life: using dietary toughness to compare the fallback signal among capuchins and implications for interpreting morphological variation. Am J Phys Anthropol 140:687-699

Zentall TR (2006) Imitation: definitions, evidence, and mechanisms. Anim Cogn 9:335-353 